\title{
Medical technology often a burden if designed without physician input
}

\author{
— Cite as: CMAJ 2018 September 10;190:E1091-2. doi: 10.1503/cmaj.109-5656
}

Posted on cmajnews.com on Aug. 21, 2018.

f you would like to hear a physician rant, simply say these three letters: EHR.

"You just feel like a data-entry clerk when you use an EHR," Dr. Gigi Osler, the incoming president of the Canadian Medical Association (CMA), said during a discussion on medical technology at the CMA Health Summit in Winnipeg.

The EHR, or electronic health record, was supposed to make life better for doctors and patients. In theory, the technology should make it easier to record, access and share patient information. In reality, however, the widespread adoption of EHRs has become an interoperability nightmare, a source of tedium and extra work for doctors, and a leading contributor to physician burnout.

"They were not designed to be a physician workflow aid or tool," said Dr. Chaitanya Dahagam, who shared the stage with Osler during the session. "The problem is that clinicians have been left out. They have been left out of the decision making, the design of the solution, and they have been told to just take it and use it."

According to Dahagam, a business development executive for the IBM Watson Health Ecosystem, this has to change. Medicine must find a better way of involving clinicians in the design of not only EHRs, but all medical technology. Otherwise, new medical tech will often be more burdensome than useful.

"The best tech is not seen, is not felt, is not heard," said Dahagam, who holds degrees in both medicine and computer science. "It just works."

This utopia is unlikely to become reality anytime soon, at least when it

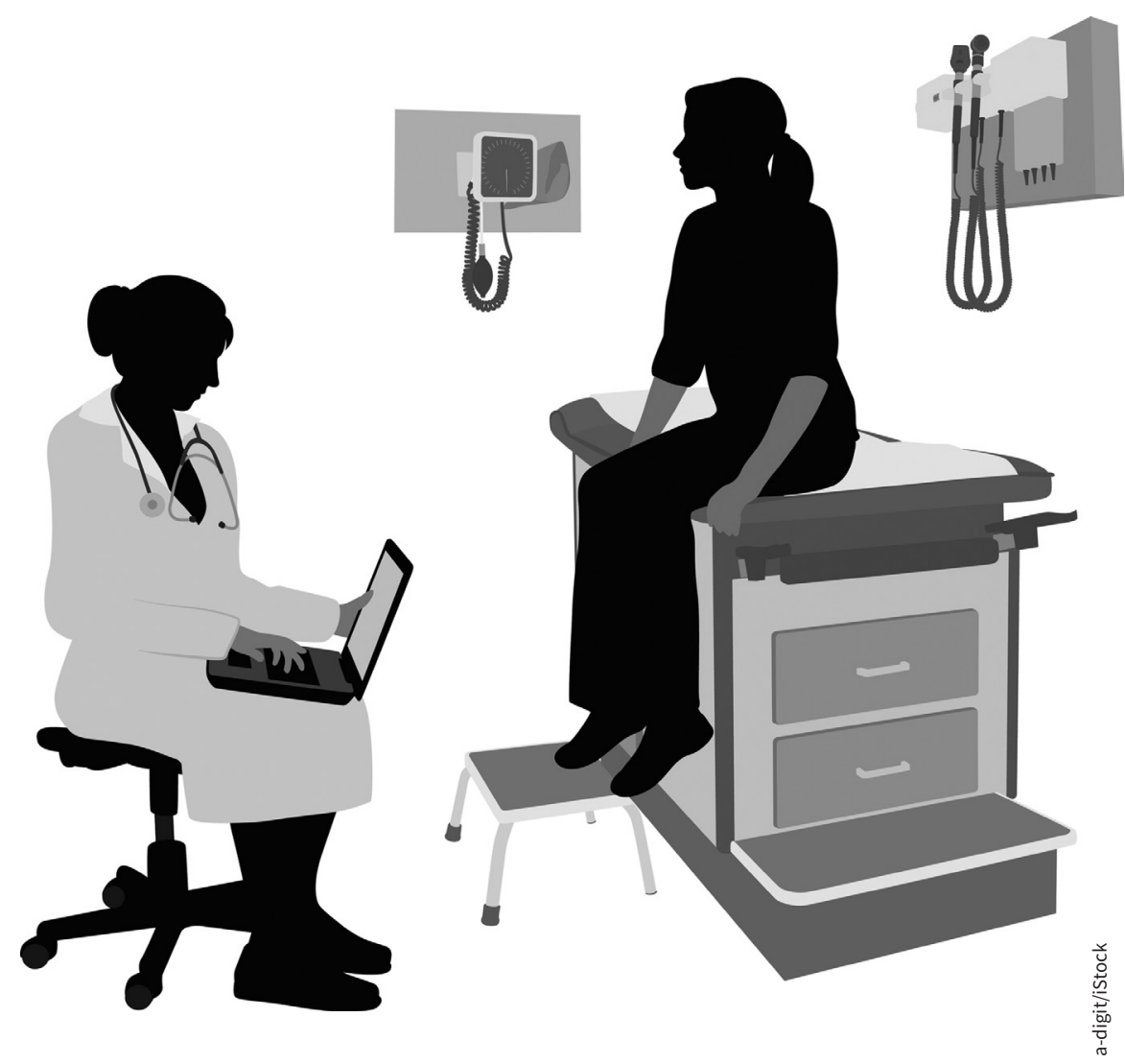

Many physicians worry that technology is dehumanizing the doctor-patient relationship.

comes to EHRs. An Ontario physician in the audience, who juggles five EHR platforms and more than 100 passwords, said doctors are constantly forced to find workarounds when dealing with electronic systems. Another common complaint is that doctors are now spending too much time looking at screens during patient visits.

"I felt that in typing and looking at a monitor, I was losing something in that connection with patients," said Osler, who now enters data into her EHR between visits with patients.

The as-yet unmet promise of interoperability between the many different EHR systems is also a source of much frustration in medicine. Patient data can't be shared among health care providers if the systems don't talk to each other. This has led some Canadian doctors to call for the creation of a single national system that would link medical practices across the country. Though there would be great 
benefits to interoperability, it won't come without a price, according to Dahagam.

"Do we truly understand what it means when data systems become interoperable," he said. "That is just more data to go through."

Indeed, data overload is another problem that technology is bringing to medical practice. Patients are generating their own health data now more than ever, through monitoring devices, health apps and private services that supply genetic informa- tion. According to Dahagam, physicians will have to learn how to integrate that information into their practices.

"Patients will want guidance, and they trust doctors and nurses more than websites," he said. "But they are going to want to feel like a partner."

There are many other challenges when it comes to making technology more useful in health care, noted Dahagam. Many of the players have different agendas. There are many aspects to consider: clin- ical, technical, business, privacy, politics. But the input of doctors will always remain vital to the success of any innovation in medicine, said Dahagam.

"Be vocal. Be pioneers. Push hard. Continue to ask, 'Why does it have to work this way? Why can't it work that way?'” he said. "The doctors coming after you are going to benefit from the fruits of your labour."

Roger Collier, CMAJ 